\title{
GUIDELINES
}

\section{SOUTH AFRICAN JOURNAL OF SPORTS MEDICINE AUTHOR INSTRUCTIONS}

All manuscripts should be submitted online: www.sajsm.org.za. If this is not feasible, the manuscript may be submitted, via e-mail, as a Microsoft Word attachment, to Mike Lambert, Editor-in-Chief, at Mike.Lambert@uct.ac.za.

\section{COPYRIGHT}

Material submitted for publication in the SOUTH AFRICAN JOURNAL OF SPORTS MEDICINE (SAJSM) is accepted provided it has not been published elsewhere. Copyright forms will be sent with acknowledgement of receipt and the SAJSM reserves copyright of the material published. The SAJSM does not hold itself responsible for statements made by the authors.

\section{AUTHORSHIP}

Authorship should be based only on substantial contribution to: (i) conception, design, analysis and interpretation of data; (ii) drafting the article or revising it critically for important intellectual content; (iii) final approval of the version to be published. All three of these conditions must be met by the authors (Uniform requirements for manuscripts submitted to biomedical journals; www.icmje.org/index.html).

\section{CONFLICT OF INTEREST}

Authors must declare all sources of support for the research and any association with the product or research topic that may constitute conflict of interest.

\section{PROTECTION OF PATIENT'S RIGHTS TO PRIVACY}

Identifying information about the patient or research subject should not be published in written descriptions or photographs unless the information is essential for scientific purposes and the patient/research subject (or parent or guardian) gives informed written consent for publication. Informed consent for this purpose requires that the patient/research subject be shown the manuscript to be published (www.icmje.org).

\section{ETHNIC CLASSIFICATION}

Work that is based on, or contains reference to ethnic classification, must indicate the rationale for this. For clarification authors are

\section{ALL CORRESPONDENCE TO:}

The Editor

South African Journal of Sports Medicine,

c/o ESSM

P.O. Box 115,

Newlands,

7725

South Africa encouraged to refer to Ncayiyana DJ: Racial profiling in medical research: what are we measuring? S Afr Med J 2007;97:1225-1226.

\section{TYPES OF MANUSCRIPTS}

Original research articles of 3000 words or less (excluding references and tables), with up to 6 tables or figures, should normally report observations or research of relevance to sports medicine and exercise science in South Africa. References should be limited to 20.

Short reports, Commentaries, or Case studies should be 1000 words or less, with 1 table or illustration and no more than 6 references.

Review articles are rarely accepted unless invited.

Letters to the editor should be no longer than 400 words with only one illustration or table.

Obituaries should not exceed 400 words and may be accompanied by a photograph.

\section{MANUSCRIPT PREPARATION}

1. The page set-up should be as follows: $2.54 \mathrm{~cm}$ margins, 1.5 line spacing, Times Roman 12 Font.

2. Each line should be numbered starting at number 1 on the first page and continuing consecutively until the last page.

3. The Title Page should have: (a) the title of the article, which should be concise but informative ( 85 characters or less, including spaces); (b) first name, middle initial, and last name of each author, with highest academic degree; (c) institutional affiliation, name of department(s) and/or institution(s) to which the work should be attributed; (d) name and address of author responsible for correspondence about the manuscript; (e) a short running header of no more than 40 characters (including spaces) placed near the bottom of the title page and identified.

4. Research articles should have a structured Abstract not exceeding 250 words (50 for short reports) comprising information under the subheadings: Objectives, Methods, Results, and Conclusions.

5. The Introduction section should provide a clear background of the study. The justification, practical importance of the study, and specific purpose or research objective should also be clearly stated.

6. The Methods section should identify the methods, apparatus (manufacturer's name and address in parentheses), and procedures in sufficient detail to allow other researchers to reproduce the results. Give references to established methods, including statistical methods (see \#7). When reporting experiments on human subjects, indicate whether the procedures followed were in accordance with the ethical standards of the responsible committee on human experimentation (institutional or regional) and whether the subjects gave their written informed consent.

7. Describe the Statistical methods with sufficient detail to enable a knowledgeable reader with access to the original data to verify 
the reported results. All data should be presented with appropriate indicators of measurement error or uncertainty (such as standard deviations or confidence intervals). Avoid sole reliance on statistical hypothesis testing, such as the use of $p$ values, which fails to convey important quantitative information. Precise $p$ values must be shown as indirect indications such as $p>0.05$ or $p=\mathrm{NS}$ are unacceptable and difficult for other researchers undertaking meta-analyses.

8. Abbreviations should be spelt out when first used in the text and thereafter used consistently. Scientific measurements should be expressed in SI units.

9. Present your Results in a logical sequence in the text, tables, and figures. Do not repeat the presentation of data in the text, tables or figures. Tables and figures should appear on separate pages. Do not discuss data in this section. Data should be presented so that the number of digits and decimals are scientifically relevant.

10. In the Discussion section emphasise the new and important aspects of the study and the conclusions that follow from them. Do not repeat in detail data or other material given in the Introduction or the Results section. Include in the Discussion section the implications of the findings and their limitations, including implications for future research. Relate the observations to other relevant studies. Link the conclusions with the goals of the study but avoid unqualified statements and conclusions not completely supported by your data. Wherever possible comment on the practical applications of the study.

\section{REFERENCES}

References should be inserted in the text as superior numbers, with the first reference being \#1 and the next reference \#2 etc. The references should be listed at the end of the article in numerical order (i.e. in order of appearance). Authors are responsible for verification of references from the original sources.

References should be set out in the Vancouver style and approved abbreviations of journal titles used; consult the List of Journals in Index Medicus for these details. Names and initials of all authors should be given unless there are more than six, in which case the first three names should be given followed by et al. First and last page numbers should be given.

Journal references should appear thus:

1. Reilly T, Edwards B. Altered sleep-wake cycles and physical performance in athletes. Physiol Behav 2007;90(2):274-284.

2. Lane $\mathrm{KN}$, Wenger HA. Effect of selected recovery conditions on performance of repeated bouts of intermittent cycling separated by 24 hours. J Strength Cond Res 2004;18(4):855-860.
3. Borg G. Perceived exertion as an indicator of somatic stress. Scand J Rehabil Med 1970;2(2):92-98.

Book references should be set out as follows:

1. Jeffcoate N. Principles of gynaecology. 4th ed. London: Butterworth; 1975. p. 96-101.

2. Weinstein L, Swartz MN. Pathogenic properties of invading microorganisms. In: Sodeman WA jun, Sodeman WA, eds. Pathologic physiology: mechanisms of disease. Philadelphia: WB Saunders; 1974. p. 457-472.

Manuscripts accepted but not yet published can be included as references followed by (in press).

Unpublished observations and personal communications may be cited in the text, but not in the reference list.

\section{COVER LETTER}

All submissions must be accompanied by a cover letter including the following information:

1. This manuscript has been read and approved by all the listed coauthors and meets the requirements of co-authorship as specified above.

2. A declaration that the manuscript is not under review with any other journal and has not been published previously.

3. A statement that prior written permission has been obtained for reproduction of previously published material (where appropriate)

4. A statement detailing any potential conflicts of interest (where appropriate).

\section{GALLEY PROOFS}

Galley proofs will be forwarded to the author before publication. Please note that alterations to typeset articles are time-consuming and need to be kept to a minimum.

\section{CHANGE OF ADDRESS}

Please notify the editorial department of any address changes so that proofs and invoices may be mailed without delay.

\section{CPD POINTS}

Authors can earn up to 15 CPD points for published articles. Certificates will be provided on request after the article has been published. 